\title{
A Mobile Butterfly-Watching Learning System for Supporting Independent Learning
}

\author{
Yuh-Shyan Chen ${ }^{1}$, Tai-Chien $\mathrm{Kao}^{2}$, Gwo-Jong $\mathrm{Yu}^{3}$, and Jang-Ping Sheu ${ }^{4}$ \\ ${ }^{1}$ Department of Computer Science and Information Engineering, National Chung Cheng University, \\ Chiayi, Taiwan, R.O.C., Email: yschen@cs.ccu.edu.tw \\ ${ }^{2}$ Institute of Education, National Dong Hwa University, Taiwan, R.O.C. \\ Email: mkao@mail.ndhu.edu.tw \\ ${ }^{3}$ Departmemt of Computer and Information Science, Aletheia University, Taiwan, R.O.C. \\ Email:yugj@wireless.mcs.au.edu.tw \\ ${ }^{4}$ Departmemt of Computer Science and Information Engineering, National Central University, Taiwan, \\ R.O.C,Email: sheujp@csie.ncu.edu.tw
}

\begin{abstract}
In this paper, we describe the development of a mobile butterfly-watching learning (BWL) system which supports independent learners by offering a new pattern of outdoor mobile learning (or called as m-learning) activities. The proposed BWL system was designed using a wireless mobile ad-hoc learning environment. In our designed system, each individual learner has a wireless handheld device, which is a PDA (Personal Digital Assistant) with an IEEE 802.11 wireless network card and a small-sized CCD camera. One instructor has a notebook computer with a Wi-Fi wireless LAN card which serves as the local server. The notebook has a complete butterfly database. All learners' wireless handheld devices and the notebook constitute a mobile adhoc learning environment. During the butterfly-watching activity, each learner takes a distinct butterfly picture, and wirelessly transmits the picture to the local server. A content-based butterfly-image retrieval technique is applied herein to search for the most closely matching butterfly information, which is returned in real time to the learner's wireless handheld device. To illustrate the effect of the BWL system, an outdoor BWL activity was actually performed at elementary school in Taiwan. This article reports on our attempts to develop a new m-learning system to support an independent learning model. We deeply believe that it is worth developing a mobile learning system to provide a possible independent-learning environment for outdoor learners.
\end{abstract}

Keywords: Butterfly-watching, content-based image retrieval, independent learning, wireless mobile ad-hoc network (MANET), m-learning.

\section{Introduction}

As educational media tend to be more mobilized, portable, and individualized, the learning form is dramatically changing. With the aid of advances in wireless communication technology [1,3,4], educational practice can now become embedded in our daily lives. For learning that extends beyond the school context, learners require independence as a life skill, to assist them in preparing for new situations and experiences. Independent learning is therefore considered an important design issue as we intend to make use of the medium capabilities of wireless communication technologies to make a difference in learning. Independent learning can assist students in acquiring the knowledge, abilities, skills, values, and motivation that enable them to analyze learning situations and develop appropriate strategies for action [5-16]. Therefore, education needs to focus on creating opportunities and experiences necessary for students to become capable, self-reliant, and self-motivated learners. In the process, independent learners develop the values, attitudes, knowledge, and skills needed to make responsible decisions and take actions dealing with their own learning. This approach to learning encourages students to produce meaning for themselves, based on their understanding of why and how new knowledge is related to their own experiences, interests, and needs. More recently, Tatar et al. [24] describes the use of handheld devices in school for lessons and learned.

A mobile learning system for scaffolding birdwatching learning was developed by Chen et al. [2] to simulate the support from wild bird guides, which share the cognitive load of bird identification when a learner is engaged in outdoor bird-watching activities. The findings provided evidence that the system not only promoted bird-identification ability but also enhanced the independence of learners. Following the model of scaffolding, this paper focuses on learning situations when the support of the instructors has been withdrawn. The proposed system intends to provide mobile aids for students to become capable, self-reliant, self-motivated, and independent learners when they are engaged in outdoor activities of exploring nature on their own. 
To evaluate the function of the system, an outdoor butterfly watching activity serves as the target research context. To support independent learning, a mobile butterfly-watching learning (BWL) system was implemented to empower the learner to engage in independent butterfly-watching activities. The activity was performed using a wireless mobile ad-hoc networking environment where each individual learner has a PDA (Personal Digital Assistant) with an IEEE 802.11 wireless LAN card, and a specialized smallsized CCD camera. One instructor has a notebook computer with a Wi-Fi wireless LAN card which serves as the local server. The notebook has a complete butterfly database. All learners' wireless handheld devices and the notebook constitute a mobile ad-hoc learning environment. The mobile butterfly-watching learning system consisted of two subsystems: a content-based butterfly image retrieval subsystem and a nature journal subsystem. The content-based butterfly image retrieval subsystem is implemented on the handheld PDA devices. Via wireless transmissions, the subsystem provides digital picture taking and immediate information retrieval for learners. The content-based image retrieval technique of the system allows learners to acquire a possible name and information on the butterfly being observed. With the aid of the subsystem, learners will be able to initiate and take actions for their own learning, and hence construct a cognitive schema for themselves. On the other hand, the nature journal subsystem enables individual learners to record the learning process and learning gains.

The rest of the paper is organized as follows. Section 2 describes basic ideas and challenges of the mobile butterfly-watching learning system. Section 3 presents the mobile butterfly-watching learning system. Section 4 presents the evaluation process of the mobile butterfly-watching learning system. And, Section 5 concludes this paper.

\section{Basic ideas and challenge}

In this paper, we attempted to develop a mobile butterfly-watching learning (BWL) system for supporting independent learning, which is based on brand-new technology of wireless networks to establish a possible mobile-learning environment. We hoped to be able to learn how to identify the family, name, ecology, and behavior of a butterfly any time and any where using the BWL system. Furthermore, we were able to take notes during the butterflywatching activity and upload our notes into the teacher's machine through a wireless Internet. Finally, those data with teacher's comments were returned to each learner's handheld device again through the wireless Internet. All these functions constitute the mobile BWL system. Each learner can independently study and learn information on butterfly ecology in an outdoor environment. In addition, the instructor or teacher can properly help learners through the BWL system. As shown in Figure 1, three knowledge domains are considered in the BWL system, the content domain consists of the mobile butterflywatching, the learning domain consists of independent learning, and the technique domain consists of wireless transmission. In order to integrate the three different knowledge domains, our mobile BWL system was developed to support an independent learning model. This new BWL system offers a new learning behavior in an outdoor nature classroom.

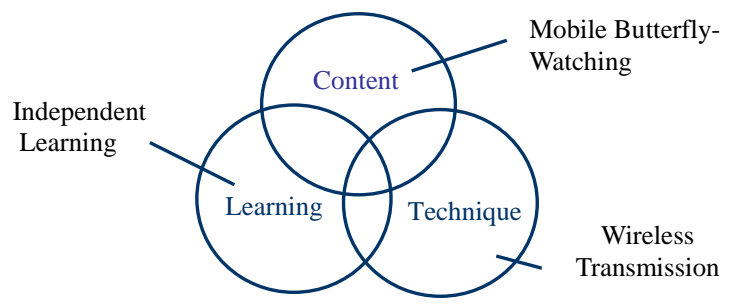

Figure 1. The BWL system.

The most important spirit of education is to help learners have self-confidence, technology, and knowledge when they attempt to seek solutions. Then, learners can independently and actively participate in their own learning. Characteristics of the independent learning model are learning knowledge more independently, and acquiring information more easily. After that, learners can extend their own learning abilities. In the beginning, we believe that the scaffold learning model easily helps and supports beginners to learn knowledge if the beginner has no self-learning ability. When a learner has sufficient knowledge and self-learning ability to overcome a problem, the instructor may relinquish control of decision making to the learner.

The challenging work of this study was determining how to integrate the independent learning model with a traditional butterfly-watching activity and to provide a BWL system. This was done by providing a userfriendly interface in a mobile learning environment. As shown in Figure 2, the independent learning model [7] includes four learning components: self-selection, selfdetermination, self-checking, and self-modification. The relations among these four components can be logically represented by a system flow, or loop, as shown in Figure 2.

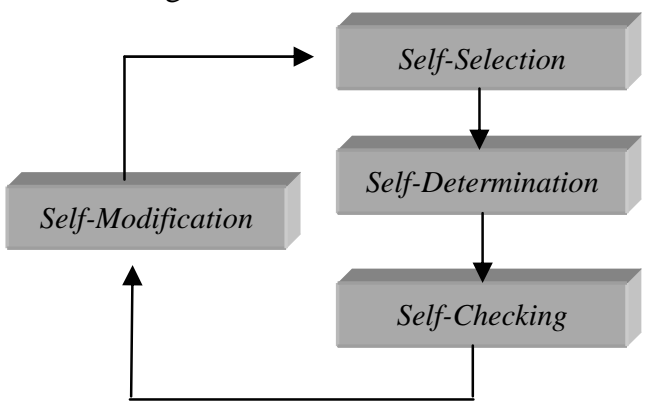

Figure 2. System flow of the independent learning method.

One other challenge of the BWL system was to integrate with a content-based image-retrieval technique [17-23] in our designed system to support 
the independent learning model. The learner could use a content-based image-retrieval system to independently acquire butterfly information without giving any data about its characteristics during the butterfly-watching activity. Meanwhile the learner could observe differences of butterflies with many similar features. The main contribution of our BWL system is that it designed to help learners to acquire the ability of self-determination, self-checking, and selfmodification. Therefore, the traditional instructor role could relinquish control of decision making. The role of the wireless network technology was to immediately provide the mobile learning knowledge. As to some immediate knowledge, it will be possible for learners to acquire information anytime and anywhere based on new wireless technologies and mobile learning systems in the near future.

The independent learning method assists learners to study when learners cannot study by adopting traditional learning methods. Therefore, we tried to implement a mobile BWL system to support an independent learning method. The four component skills of the independent learning model are (1) selfselection, (2) self-determination, (3) self-modification, and (4) self-checking. In the following, we explain the four component skills in detail as a way to implement the independent learning method.

\section{The Mobile Butterfly-Watching Learning (BWL) System}

\subsection{The wireless mobile ad-hoc learning environment}

A learning flow of the mobile butterfly-watching activity is shown in Figure 3. Each learner has a PDA with an IEEE 802.11b wireless network card and a color CCD camera, while one instructor has a notebook computer with an IEEE 802.11b wireless network card, which serves as the local server. This notebook has a complete database of butterflies in Taiwan. All of these hardware components form a wireless mobile ad-hoc learning environment [2-4]. Accordingly, learners can take some pictures using the PDA's CCD anytime and anywhere. There is a great amount of butterfly-related information which is returned from our local server. The learner can upload the pictures to the local server based on the wireless mobile ad-hoc networking environment [2-4]. A content-based image-retrieval subsystem is applied to automatically search for the most closely matching butterfly records, and all related information is returned to the learner. In other words, our outdoor learning system offers real-time butterfly learning information. The system provides learners with a data mining interface for butterfly searching, which is in a pleasurable environment, to unconsciously create a full set of knowledge for a certain butterfly or its related information. In addition, the learners must properly be supported during the learning process, so that they can change their own learning attributes. In different actual practice sessions, the instructor assisted students in accordance with their individual learning efficiencies.
The essence of the independent learning method is to assist learners in accordance with their aptitude.

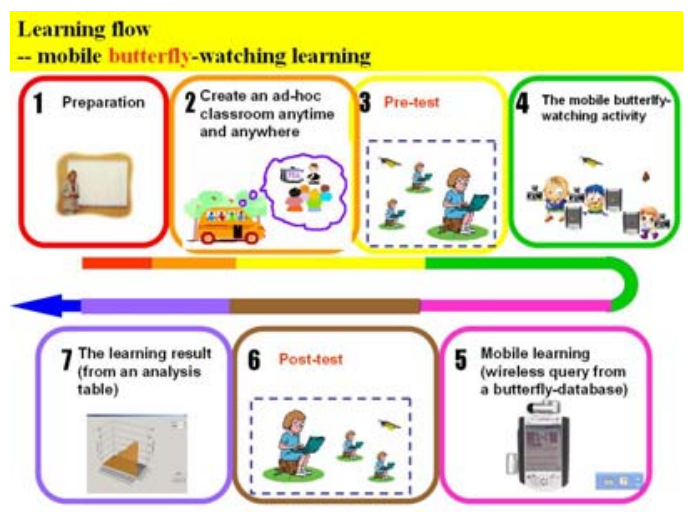

Figure 3. Learning flow of BWL system.

\subsection{Implementation of Self-Selection}

The characteristics of the independent learning model emphasize that learners are learning freely to choose which butterfly species is interesting. Therefore we provide an automatic tool to obtain images in each butterfly-watching activity. The details of selfselection implementation are described as follows. We formed a wireless mobile ad-hoc network using handheld devices (PDAs) with wireless network cards, a color CCD camera, and a notebook computer with a wireless LAN card, as shown in Figure 4. By participating in the butterfly-watching activity, each learner was able to take different butterfly pictures using his/her own color CCD camera, and transferred the butterfly image file in real time from the PDA to a local server, a notebook computer, using the wireless mobile ad-hoc network routing protocol [1-4]. The butterfly image files were processed in our contentbased butterfly image retrieval system. Finally, our system transferred the most closely matching butterflydata files such as: butterfly images, ecological data, and related information to the learner's mobile handheld device. Learners were able to joyfully and easily study the detailed information and ecological data about the butterfly they had just observed. In addition, the similarly matching butterfly-data files could be helpful to learners who would like to learn related data.

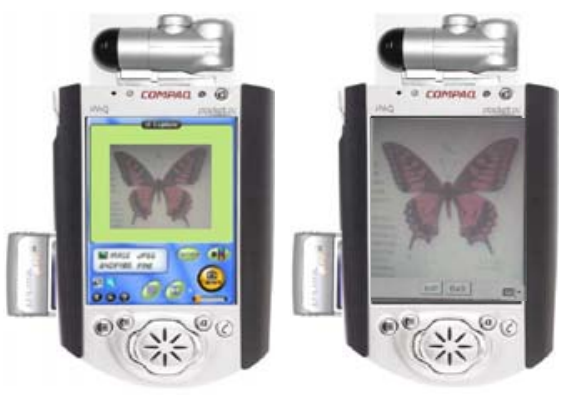

Figure 4. Interface of the BWL system. 


\subsection{Implementation of Self-Determination}

There are many butterflies with similar features in the world. Consequently, the content-based butterfly image-retrieval system produces the most closely matching butterfly records from our butterfly database. To achieve the goal of self-determination, we designed an outdoor nature journal subsystem. The goal was to train the learners to have the skills to independently choose the precise answer (butterfly) from all provided estimated butterfly data files with similar features. Also, learners can indirectly obtain more knowledge from those messages about butterflies with similar features. Thus, we had to allow learners to selforganize the knowledge as a part of the learning process; moreover, learners can lay out and construct their knowledge to form complete knowledge by themselves.

In the outdoor nature journal subsystem of the BWL system, learners can freely choose which butterfly species is interesting. In our image database, however, there is an abundance of similar butterflies in Taiwan, and there are many butterflies with similar features. For this reason, a content-based butterfly image-retrieval subsystem was provided to help the learner make the correct decision. The main operation is demonstrated as follows. Each learner first took pictures using the PDA's color CCD camera and then transferred the pictures to the notebook computer, as illustrated in Figure 5. After that, the content-based butterfly image-retrieval subsystem acquired the pictures, and our system automatically compared the new incoming picture with all pre-stored images in our database. Finally, the content-based butterfly imageretrieval subsystem filtered out the most likely butterfly-data files with similar features, and finally transferred the top three possible butterfly-data files back to the learner's PDA, as shown in Figure 6.

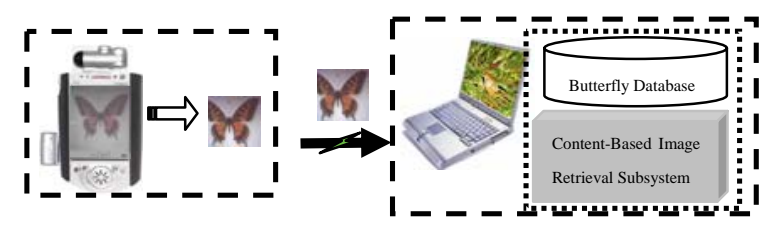

Figure 5. The PDA transfers a picture to the Server.

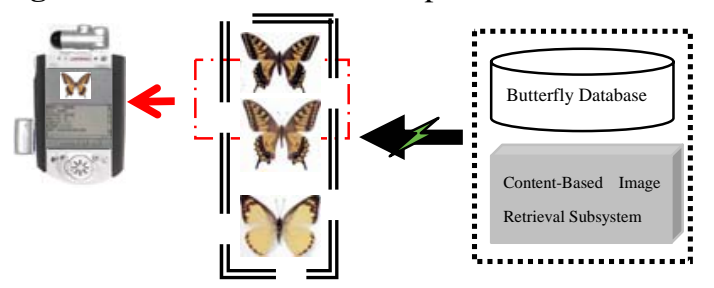

Figure 6. The server returns the result to the PDA.

It is possible that learners have no butterfly information, therefore an outdoor nature journal subsystem was designed to assist and train learners and beginners to develop independent learning ability. The operation is described below. When learners obtained information from our content-based butterfly imageretrieval subsystem, it was possible that no any correct answer was obtained. Our system additionally provided a web-based wireless querying subsystem to search for possible butterfly information by only giving the butterfly's features step by step, as illustrated in Figure 7. An example of the nature journal subsystem is shown in Figure 8. Learners used the nature journal subsystem to write notes to describe their observed results, the butterfly watching process, and experience. Each learner's observed results may or may not be correct, since this observed result is an independent learning result. These notes were uploaded into the instructor's notebook by wireless transmission. The instructor, who may be real-time or off-time, replied with a proper comment or statement of judgment to each learner, as shown in Figure 9.
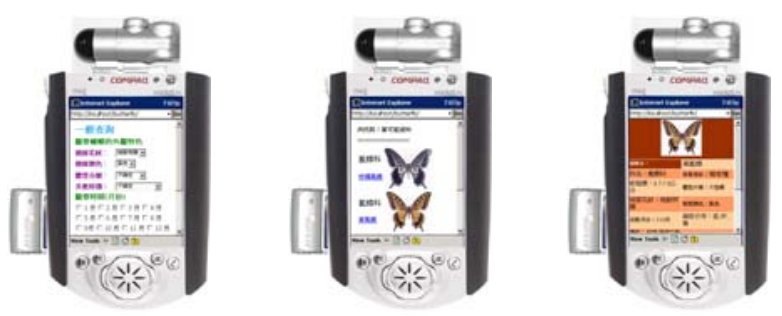

Figure 7. A web-based wireless querying subsystem.
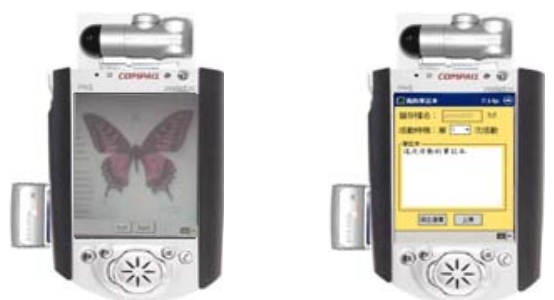

Figure 8. The interface of nature journal subsystem for learner.

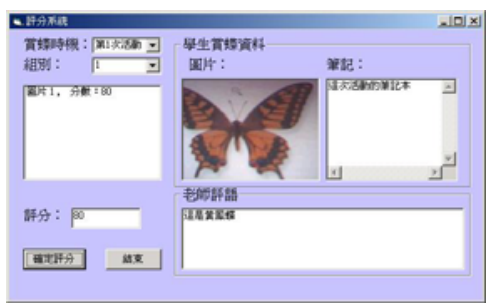

Figure 9. The nature journal subsystem for Instructor.

\subsection{Implementation of Self-Modification}

Implementing self-modification of the BWL system was mainly based on the dynamic assessment [2]. The learning system provides different assisted learning skills according to those students who have different learning abilities and achievements. Basically, our learning system provides different amounts of selected 
items for different learning achievement levels. Distinguishing different learning skills is based on learners' pre-test/post-test results and scores from the nature journal subsystem. Because there are many butterflies that have similar features in the world, learners may obtain incorrect information during the self-determination. To avoid making an incorrect decision during the learning procedure, our system aims to help the learner quickly modify the knowledge and to train the learner to have independent learning ability. The operation is described as follows. We first provided a teacher-modification interface so that the instructor could browse all notes from all learners, as shown in Figure 9. The instructor examined the learners' nature journal, and returned the scores and comment/statement of judgment to the learners using the teacher-modification interface. Consequently, the learner could look at the comment/statement of judgment, sent from the instructor, in his/her own PDA. Furthermore, the learner could check his/her previous observed results and could dynamically and immediately adjust his/her knowledge of the butterfly. The flowchart of a previous description is given in Figures 10 and 11. Lastly, our system provided pre-test and post-test to automatically evaluate the learning achievement. Finally, this system aims to provide an independent learning system for learners.

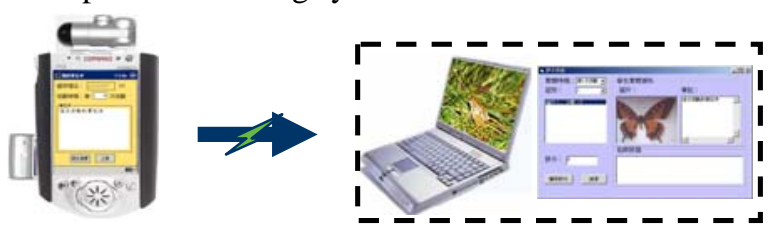

Figure 10. Uploading the nature journal into the local Server.
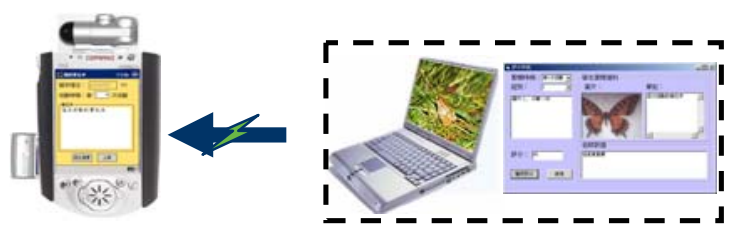

Figure 11. The instructor returns the information to the learner.

\subsection{Implementation of Self-Checking}

To implement self-checking, we provided pre-test and post-test subsystems. To increase impressions about butterflies, more user-friendly learning interfaces were designed and offered. In different actual trials, the instructor assisted learners in accordance with their learning ability. Therefore, we implemented a selfchecking system to achieve the purpose of the dynamic assessment. In the process of the dynamic assessment, we designed different styles of evaluation sheets on PDAs to evaluate the learning ability of learners. All data including problems, hints, and answers were automatically retrieved from the butterfly databases.
Because we stored a large amount of butterfly data in the databases, we provided a user-friendly interface to do the assessment. In this way, the instructor could assign questions by easily using the interface. In particular, we also added picture questions in the selfchecking system of the butterfly-watching activity. There are more-interesting functions for learners when they use the system. This will help learners have more impressions about the butterflies. The interface with the assessment subject of a butterfly and selected items for learning on the instructor's notebook computer are shown in Figure 12.
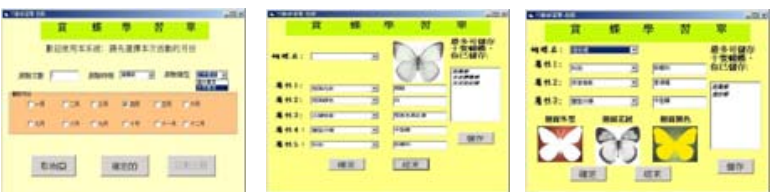

Figure 12. The assessment subject of butterfly and selected items for learning.

In our system, we can set up the time of the activities and tests which a learner has to complete. We demonstrate the process of assessment of a learner with an example. In our database, there are a number of records of butterflies in Taiwan. The instructor could select about 10 kinds of butterflies for pre-test and post-test, as shown in Figure 12. Our system filters out some useful knowledge to support the instructor. The butterfly information contains the family of the butterfly, the host plants, its natural habitat, the color and features of the wing, other features of the butterfly, the level of protection, and so on. Based on this function, the instructor can easily and quickly find a solution from the database. According to the conditions of each butterfly-watching activity, our system provides two different kinds of test sheets for the instructor, as shown in Figure 12. One only gives the butterfly's name, and the learner must answer all questions, including the image-questions. Another one gives the butterfly's image, and the learner must answer the butterfly name, and so on. These examples are shown in Figure 13. Further, the test results in realtime are displayed on the instructor's notebook and learner's PDA, as shown in Figure 14.
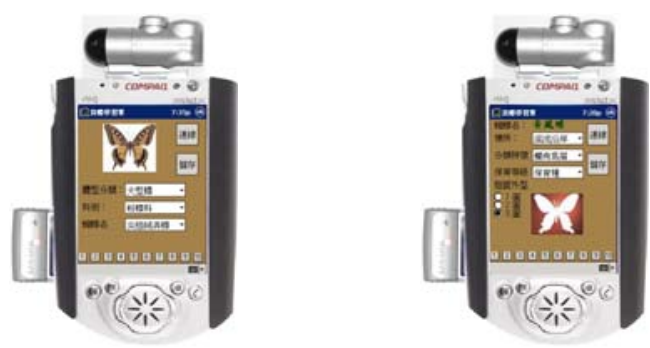

Figure 13. Two kinds of the test sheet for Learners. 

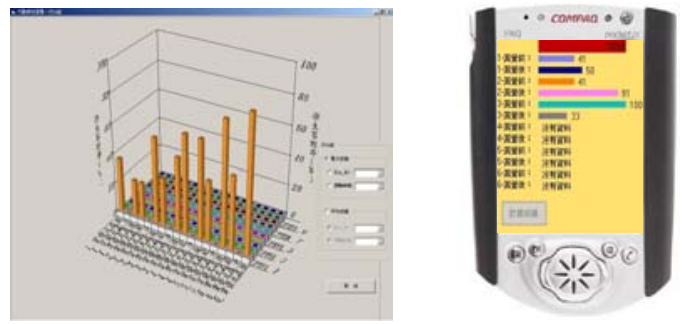

Figure 14. The evaluated results are produced automatically in notebook and PDA.

To adaptively examine the student's learning ability, we provide different levels of difficulty on our assessment sheet or on-line test system. For example as shown in Figure 15, when the average score is less than $40 \%$, the system provides the learner moredifficult questions. The number of selection items is three. If the average score is between $40 \%$ and $60 \%$, the number of selection items is four, as shown in Figure 16. Finally, if the average score is higher than $60 \%$, the number of selection items is five. When a learner needs a higher support level, we provide him/her fewer selection items, since there is a higher probability of selecting the correct items.

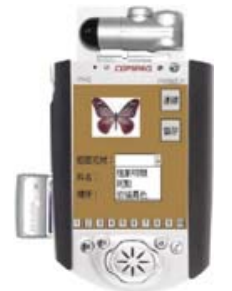

Figure 15. An example of assessment average $<40 \%$.

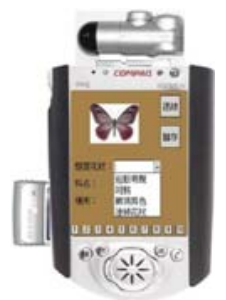

Figure 16. An example of an assessment average between $40 \%$ and $60 \%$.

\section{Evaluation Process 4.1. Research Design}

In our previous study [2], we scaffolded the learners' ability and independence by shifting the task responsibility from the expert to the learners with the learning system through three-phase design of experiments. Following the model of scaffolding, this study focuses on the learning situations that the support from the expert has been withdrawn (i.e. the last phase of experiment in the previous study). We intend to provide evidence that the proposed system can be the ideal mobile aids for students to become capable, self-reliant, self-motivated, and independent learners while they engaged in outdoor nature exploring activities on their own. But it does not mean the learners need no scaffolds and modeling from the expert beforehand. However, we believe the fading process could be shorter with the help of the proposed system.

The experiment for formative evaluation is conducted in the fall semester of 2003. One elementary school is chosen from the three participant schools of our previous study [2]. A class of 24 fivegraders is randomly assigned into two groups, the BWL-assisted group and the guidebook-assisted group. Each group was lead by a natural sciences teacher and a butterfly guide (i.e. the expert). The students worked in pairs as teams.

The experiment consists of three butterfly-watching activities for independent learning. Before the experiment, the students have to experience three butterfly-watching activities lead by the guide. The guide confirmed the name and key features of the species being observed directly. In the meantime, teams from the BWL group practice for picture taking and information searching with the system. Teams from the guidebook group practice for picture drawing and information searching with the guidebook. After the training and modeling, students are able to explore and identify the butterflies they watch in the nature environment on their own with the help of our system or guidebook in the next three activities.

All the butterfly-watching activities are hold on a local butterfly-breeding farm, which is 20-minute bus ride away from the school. The guide (i.e. the owner of the farm) has specified 17 species of butterflies appeared in the farm during the seasons and arranged them into six activities as target species for observation. Basically, the learners are able to encounter three new species and three old species in each activity. Based on the six species arranged for each activity, the guide would pick six key features for each species as multiple-choice questions in pretest and posttest. Pretest and posttest are conducted to each team before and after the activity on PDA. Team performance on the tests is based on the percentage of correctness.

In the activity, the teacher has to carry a notebook as a local server. Each team is given a PDA or a copy of guidebook depending on the group it belongs to. The butterfly-watching procedures of independent learning are:

1. Self-selection process: The learners in the team find one of the target butterflies on interest and take a close picture of it.

2. Self-determination process: After that, the learners transfer the picture and give searching conditions based on features they identified to the system. According to the searching results, the learners are able to determine the name of the butterfly being observed.

3. Self-modification process: The system further suggests the possible name list of the observed butterfly through image mapping technique. This 
gives the chance for the learners to modify their previous searching conditions and conclude to different determination.

4. Self-checking process: The learner records their learning process to the journal, including picture of the searching conditions, searching results, suggestions from image mapping, and each determination they make. The information recorded on the journal allows the learners to check for correctness after the activity.

The data collected for evaluation includes test results, journals, and videotapes of each activity. Data are compared between activities, teams, and species to evaluate the growth of students' ability of independent learning and how they benefit from the system.

\subsection{Result}

By the end of November 2003, four activities have been completed. The fourth activity was the only activity of independent learning. It was just held on Nov. 26 and the posttest data has not been collected yet. Table 1 presents the means and the standard deviations of the pretest and the posttest for each activity.

Table 1. Means and standard deviations of pretest and posttest for each activity

\begin{tabular}{lccccc}
\hline & \multicolumn{2}{c}{ BWL } & \multicolumn{2}{c}{ Guidebook } \\
Activity & Test & mean & s.d. & Mean & s.d. \\
\hline One & Pretest & & & & \\
$(10 / 1)$ & & 30.33 & 09.67 & 29.50 & 14.56 \\
& Posttest & 42.67 & 21.57 & 37.33 & 16.48 \\
Two & Pretest & & & & \\
$(10 / 22)$ & & 44.17 & 11.97 & 47.33 & 12.36 \\
& Posttest & 67.17 & 14.34 & 55.33 & 14.71 \\
& Pretest & 67.83 & 11.74 & 58.67 & 18.61 \\
Three & Posttest & & & & \\
$(11 / 12)$ & & 82.17 & 09.68 & 74.33 & 18.77 \\
\hline Four & Posttest & & & & \\
$(11 / 26)$ & & 71.33 & 05.85 & 59.67 & 14.54 \\
\hline
\end{tabular}

Figure 17 shows the progress curves of the pretest and posttest means of the activities for both groups. The mean scores of BWL group show significant progress before and after each activity. For the first three activities, the performance level maintains between activities. Although the performance level of activity 3 posttest did not maintain to activity 4 pretest, the score was still a little bit higher than the activity 3 pretest score. The performance of the guidebook group progress steadily from activity 1 pretest to activity 3 posttest. Although the ranges of progress in activities are not as significant as the BWL group, the performance level progresses even between activities. For the activity 3 and activity 4 pretest, the performance of the guidebook group shows almost the same pattern as the BWL group. The possible reason could be the target species for activity four might be harder to identify than before.

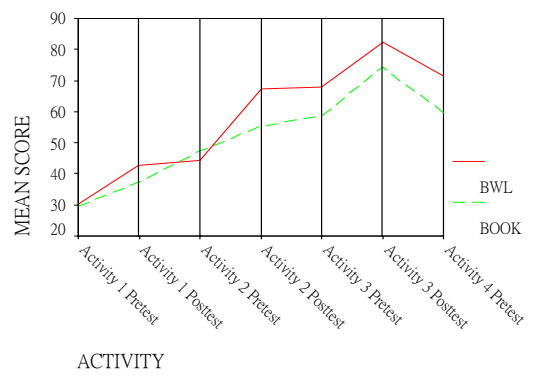

Figure 17. The progress curves of the pretest and posttest means of the activities for both groups

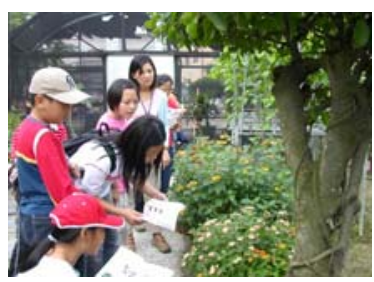

(a)

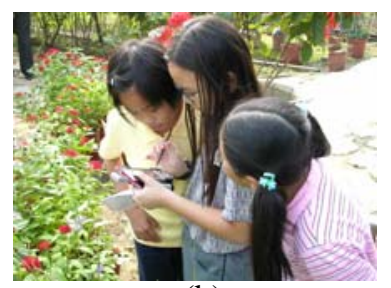

(b)
Figure 18. (a) The guidebook group and (b) the BWL group.

\section{Conclusion}

In this paper, we report on the development of an independent-learning-based mobile butterfly-watching learning (BWL) system, which aims to construct an outdoor mobile-learning activity under up-to-date wireless technology. The proposed BWL system was designed on a wireless mobile ad-hoc network. A major element of our system is that it allows learners to take actions dealing with their own learning. Through content-based image-retrieval techniques, all beginners who go outside for butterfly watching can more quickly and easily acquire information on butterflies they observe. One other contribution of this system is the nature journal subsystem, which is an integrated learning method including an independent learning method and brand-new wireless network information technology. This work aimed to provide excellent experiences for future classroom learning platforms.

\section{Acknowledge}

This work was supported by learning technology, sponsored by the Ministry of Education, Taiwan: $91 \mathrm{~A}-$ H-FA07-1-4 and 92A-H-FA07-1-4.

\section{References}

[1] D. B. Johnson and D. A. Maltz, "Dynamic Source Routing in Ad Hoc Wireless Networks", Mobile Computing, edited by Tomasz Imielinski and Hank Korth, Chapter 5, pp. 81-153, 1996.

[2] Y.-S. Chen, T.-C. Kao, and J.-P. Sheu, "A Mobile Learning System for Scaffolding Bird Watching Learning", Journal of Computer Assisted 
Learning, (special issue on "Wireless and Mobile Technologies in Education"), Vol. 19, No. 3, pp. 347-359, Sep. 2003.

[3] Y.-S. Chen and K.-C. Lai, "MESH: Multi-Eye Spiral-Hopping Protocol in a Wireless Ad Hoc Network", IEICE Transactions on Communications, Vol. E84-B, No. 8, pp. 22372248, Aug. 2001.

[4] Y.-S. Chen, T.-S. Chen, and C.-J. Huang, "SOM: Spiral-Fat-Tree-Based On-Demand Multicast Protocol in a Wireless Ad-Hoc Network", Computer Communications, Vol. 25, Issue 17, pp. 1684-1695, Nov. 2002.

[5] C. Kesten, Independent Learning, Regina, Sask.: Saskatchewan Education, 1987.

[6] H. Herber, and J. Nelson-Herber, "Developing Independent Learners”, Journal of Reading, Vol. 30, No.7, pp. 584-589, April. 1987.

[7] A. Tough, "Self-directed learning: Concepts and practices", In T. Husen, and T. N. Postlethwaite, eds. The International Encyclopedia of Education, 8. Oxford: Pergamon, 1986.

[8] H. McDonald, and L. Ingvarson, "Technology: A Catalyst for Educational Change”, Journal of Curriculum Studies, Vol. 29, No. 5, pp. 513-527, Oct. 1997.

[9] J. Weasmer, and A. Woods, "Encouraging Student Decision Making”, Kappa Delta Pi Record, Vol. 38, No. 1, pp. 40-42, Fall 2001.

[10]B. Musthafa, Content Area Reading: Principles and Strategies to Promote Independent Learning, 1996.

[11]D. Marsh, "Computer Conferencing: Taking the Loneliness Out of Independent Learning", Language Learning Journal, No.15, pp. 21-25, Mar. 1997.

[12]K. Houston, and A. Lazenbatt, “A Peer-Tutoring Scheme to Support Independent Learning and Group Project Work in Mathematics”, Assessment \& Evaluation in Higher Education, Vol. 21, No. 3, pp. 251-266, Sep. 1996.

[13] A. Sivan, R. W. Leung, and C.-C. Woon, and D. Kember, "An Implementation of Active Learning and Its Effect on the Quality of Student Learning", Innovations in Education and Training International, Vol. 37, No. 4, pp. 381-389, Nov. 2000.

[14]L. E. Maitland, "Ideas in Practice: Self-Regulation and Metacognition in the Reading Lab", Journal of Developmental Education, Vol. 24, No. 2, pp. 26-36, Win. 2000.

[15] G. Lafferty, "Equity, Access and Independent Learning: Maximising the Outcomes for Mature Age Students", Australian Journal of Adult and Community Education, Vol. 36, No. 2, pp. 103111, Jul. 1996.

[16] R. L. Martens, M. M. A. Valcke, and S. J. Portier, "Interactive Learning Environments to Support Independent Learning: The Impact of Discernability of Embedded Support Devices", Computers \& Education, Vol. 28, No. 3, pp. 185197, Apr. 1997.
[17] X. Li, S.-C. Chen, M.-L. Shyu, and B. Furht, “An effective content-based visual image retrieval system", in Proceedings. of $26^{\text {th }}$ Annual International of Computer Software and Applications Conference, pp. 914-919, Aug. 2002

[18] N. Jhanwar, S. Chaudhuri, G. Seetharaman, and B. Zavidovique, "Content based image retrieval using optimum Peano scan”, in Proceedings. of 16th International Conference on Pattern Recognition, Vol. 4, No. 4, pp. 130-133, 2002.

[19] A. Kak, C. Pavlopoulo, A. Kak, and C. Pavlopoulou, "Content-based image retrieval from large medical databases", in Proceedings. of First International Symposium on 3D Data Processing Visualization and Transmission, pp. 138-147, June. 2002.

[20] T. S. Huang, X. S. Zhou, M. Nakazato, Y. Wu, and I. Cohen, "Learning in content-based image retrieval", in Proceedings. of The 2nd International Conference on Development and Learning, pp. 155-162, June. 2002.

[21] W.-N. Lie, W.-H. Peng, and C.-H. Chuang, "Efficient content-based CT brain image retrieval by using region shape features", in Proceedings. of 2002 IEEE International Symposium on Circuits and Systems, Vol. 4, No. 5, pp. 157-160, 2002

[22] R.O. Stehling, M.A. Nascimento, and A.X. Falcao, "An adaptive and efficient clustering-based approach for content-based image retrieval in image databases", in Proceedings. of 2001 International Symposium on Database Engineering \& Applications, Grenoble, France pp. 356-365, 2001.

[23] G.-D. Guo, A.K. Jain, W.-Y. Ma, and H.-J. Zhang, "Learning similarity measure for natural image retrieval with relevance feedback", in Proceedings. of 2001 IEEE Computer Society Conference on Computer Vision and Pattern Recognition, Vol. 1, No. 2, pp. 731-736, 2001.

[24] D. Tatar, J. Roschelle, P. Vahey, and W. R. Penuel, "Handhelds go to school: lessons learned”, IEEE Computer Magazine, Vol. 36, No. 9, pp. 30-37, Sep. 2003. 